16. Jeffery RW, Kelder SH, Forster JL, et al. Restrictive smoking policies in the workplace: Effects on smoking prevalence and cigarette consumption. Prev Med 1994;23:78-82.

17. Patten CA, Gilpin E, Cavin SW, et al. Workplace smoking policy and changes in smoking behaviour in California: A suggested association. Tobacco Control 1995;4:36-41.

18. Pederson LL, Bull SB, Ashley MJ. Smoking in the workplace: Do smoking patterns and attitudes reflect the legislative environment? Tobacco Control 1996;5:39-45.

19. Longo DR, Brownson RC, Johnson JC, et al. Hospital smoking bans and employee smoking behaviour. Results of a national survey. JAMA 1996;275:1252-57.

20. Olive KE, Ballard JA. Changes in employee smoking behaviour after implementation of restrictive smoking policies. Southern Med J 1996;89:699-706.

21. Brown KS, Pederson LL. Smoking cessation. Chapter 4, in: Stephens T, Morin M (Eds.), Youth Smoking Survey, 1994: Technical Report. Ottawa: Minister of Supply and Services Canada, 1996;54-74.

22. Clarke V, White V, Hill D, Borland R. School structural and policy variables associated with student smoking. Tobacco Control 1994;3:33946.

23. Glynn TJ, Greenwald P, Mills SM, Manley MW. Youth tobacco use in the United Statesproblem, progress, goals, and potential solutions. Prev Med 1993;22:568-75.

24. Reid DJ, McNeill AD, Glynn TJ. Reducing the prevalence of smoking in youth in Western countries: An international review. Tobacco Control 1995;4:266-77.

25. Epps RP, Manley MW, Glynn TJ. Tobacco use among adolescents: Strategies for prevention. Pediatric Clinics of North America 1995;42:389402.

26. Ashley MJ, Cohen J, Bull SB, et al. Smoking in Ontario: Analysis of data from the 'Q \& Q' study. Report prepared for Health Canada and the Ontario Ministry of Health. Toronto, Ontario Tobacco Research Unit, March 1997.

Received: August 12, 1997

Accepted: February 9, 1998

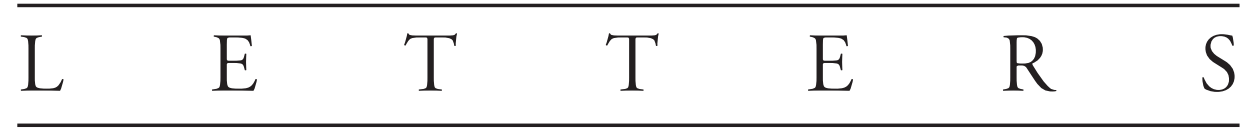

\section{Urban Air Pollution and Mortality}

Dear Editor:

Re: Burnett RT, Cakmak S, Brook JR. The effect of the urban air pollution mix on daily mortality rates in 11 Canadian cities. Can J Public Health 1998;89(3):152-56.

In the above article, Burnett et al. reported that $8.2 \%$ of all non-accidental deaths from 1980-1991 were attributed in a time-series analysis to four gaseous air pollutants, nitrogen dioxide, sulphur dioxide, ozone and carbon monoxide. Such a high risk of premature mortality from contemporary levels of the four gases is surprising, as is the absence of risk from $\mathrm{PM}_{2.5}$ (respirable particulate matter less than 2.5 $\mu \mathrm{m}$ in average diameter). These surprising results, if confirmed, make this paper very important in a public health context by suggesting that a measurable, perhaps even dramatic improvement in population health can be obtained by reducing gaseous air pollution. However, these findings must be critically evaluated.

The high mortality indicated in Burnett et al.'s paper is inconsistent with other studies, and the authors do not acknowledge those differences. Time-series studies, in which area monitors serve as surrogate data for individual exposures and study populations, are assumed to be homogeneous (i.e., ecological study designs) and are useful in detecting associations, such as that in the present study, but such hypothetical associations require validation by other methods using other data sets. The authors' analysis ignores a massive amount of traditional epidemiology, human clinical and animal toxicology research that finds no mortality resulting from exposures to the four gases at the low levels ${ }^{1}$ typical in Canada.

Burnett et al. do not provide sufficient details about their models to allow critical analysis. A host of investigator-specific decisions are incorporated into the statistical models and analyses, and many of these decisions influence the reported associa- tions. These same authors have previously stated, "detecting an air pollution effect with time-series methodology requires the appropriate use of complex statistical techniques in order to tease out a relatively small signal from a forest of noise. The art of the analysis is to remove the proper amount of unwanted temporal variability in the time series, thus revealing the 'true' air pollution signal." A means of confirming the validity of the "signal" in the present study is needed.

Among specific concerns, the selection of averaging time, days lagged and filters should be made a priori and should be based on some objective statistical criteria, such as what variable reduces autocorrelation to a minimum or causes the largest decrease in the log likelihood function, not based on maximizing relative risks. The use of biological criteria would be even more persuasive as a basis of modeling decisions and might suggest who (e.g., what sub-population) is at risk, which is a critical issue. The paper fails to provide statistical criteria used to select various model parameters, omits exposureresponse functions, and fails to seriously treat biological plausibility. Rather, the authors note that different gases contribute to the overall risks differently in each city with no consistent pattern within regions. For example, Table IV shows the "increased risk" from nitrogen dioxide varies in different cities from 0 to $9.4 \%$ and that of sulphur dioxide from -0.3 to $2.9 \%$. Is such variation indicative of a real, consistent effect, or is this an argument against causality?3

Unfortunately, Burnett et al. do not address these critical issues, yet they appear to have succeeded where other investigators have failed, using the time-series approach alone to identify a combination of the four air pollutants (most of which are correlated) as a major cause of increased mortality at low ambient levels. ${ }^{4-6}$

The strength of the opinions expressed in the article is disquieting for the additional reason that the four gases were ...see Letters, page 238 
22. Office of the Chief Coroner of British Columbia. Report of the Task Force Into Illicit Narcotic Overdose Deaths in British Columbia. British Columbia: Ministry of Attorney General, 1994.

23. Ashley R. Heroin: The Myths and the Facts. New York: St. Martin's Press, 1972; 2-35.

24. Dunsmuir M. Drug Laws and Trafficking Patterns in Canada. [Ottawa:] Law and Government Division. Library of Parliament. Canada. 1990.

25. Grandy T. New Occupational Hazards of Career Addicts: Main Line Intravenous Needs
Assessment (MINA). Halifax: Main Line Needle Exchange, 1995.

26. Counsellors at Drug Dependency Services, Nova Scotia Department of Health. Personal communication

27. Archibald C, Ofner M, Patrick D, et al. The Point Project: A Study of Risk Factors for HIV Infection among Vancouver's Injection Drug Use Community, Summer of Final Results. Vancouver: Laboratory Centre for Disease Control, HIV/AIDS Epidemiology Division, 1996.
28. Gold MS. Cocaine. New York: Plenum Medical Book Co., 1993; 1-36.

29. Erickson PG. The Steel Drug. Toronto: Lexington Books, 1987; 3-22.

30. National Task Force on HIV, AIDS and Injection Drug Use. HIV, AIDS and Injection Drug Use. A National Action Plan. [Ottawa:] Canadian Centre on Substance Abuse and the Canadian Public Health Association, 1997. ISBN 1-896323-22-7.

Received: September 22, 1997

Accepted: March 17, 1998
Letters, from page 228

shown to "explain" all the mortality previously associated with PM (particulate matter) or its surrogate, sulphate. These same authors have previously attributed significant adverse health effects to sulphate. ${ }^{7}$ Their present concern about the four gases is based on an inappropriate comparison of risk reductions derived from two very different models: results from a multipollutant model (for 5 Canadian cities) incorporating the four gases but not PM, are compared to results from a single pollutant model (in 6 U.S. cities) for $\mathrm{PM}_{2.5}$ and sulphate during a different time period. ${ }^{8}$ This comparison does not appear to be appropriate if PM does not improve the predictive power of the multi-pollutant model for the air pollution mix, on morbidity and mortality. ' Similarly, risks due to different pollutants should be compared using comparable units of measure that take into account differences in means and variances.

Given the inconsistent city-to-city patterns for gaseous pollutants observed by Burnett et al., as well as the inconsistency of their results with others, more research appears to be warranted. For example, it would seem that any examples of risk reductions should be based on data for gaseous pollutants, PM and sulphate in the same cities, over the same time frame, and using the same multi-pollutant model. In addition, validation of these findings by other methods and using other populations are critically needed to reconcile the results from ecological time-series studies with the body of evidence supporting current air quality objectives.

If these surprising results are confirmed, the methods of Burnett et al. should be applied to a variety of control strategies in a comprehensive and planned process in order to contribute to gains in population health. The present study raises an interesting hypothesis which begs questions as to the relative importance to human health of gaseous and particulate matter, and who is affected; it is inappropriate as the basis for a specific risk management decision of the type in their example.

\section{G.C. Granville, Manager \\ Toxicology and Materials Safety \\ Shell Canada Limited \\ 400 - 4th Avenue, S.W. \\ Calgary, $A B$ T2P $2 H 5$}

\section{L.A. Gephart, Group Head}

Exxon Biomedical Sciences, Inc. Mettlers Road CN2350

East Millstone, NJ 08875-2350

U.S.A.

\section{R.T. Keefe, Sr. Staff Toxicologist \\ Imperial Oil Limited \\ 111 St. Clair Avenue West \\ Toronto, ON M5W $1 K 3$}

\section{REFERENCES}

1. Health Canada, 1997. Health and environment: Partners for life. p 63.

2. Cakmak S, Burnett R, Krewski D. Adjusting for temporal variation in the analysis of parallel time series of health and environmental variables. J Expos Anal Environ Epidemiol 1998;8(2):129-44.

3. Gamble JF, Lewis RJ. Health and respirable particulate (PM10) air pollution: A causal or statistical association? Environ Health Perspect 1996;104(8):838-50.

4. Health Effects Institute, March 1997. Particulate air pollution and daily mortality: Analysis of the effects of weather and multiple air pollutants. The phase I.B report of the particle epidemiology evaluation project. Samet JM, Zeger SL, Kelsall JE, et al.

5. Moolgavkar SH, Luebeck EG, Hall TA, et al. Air pollution and daily mortality in Philadelphia. Epidemiology 1995;6(5):476-84.
6. Li Y, Roth HD. Daily mortality analysis by using different regression models in Philadelphia county, 1973-1990. Inhal Tox 1995;7:45-58.

7. Burnett RT, Dales RE, Raizenne ME, et al. Effects of low ambient levels of ozone and sulfates on the frequency of respiratory admissions to Ontario hospitals. Environ Res 1994;65:172-94.

8. Schwartz J, Dockery DW, Neas LM. Is daily mortality associated specifically with fine particles? J Air \& Waste Manage Assoc 1996;46:927-39.

9. Burnett RT, Cakmak S, Brook JR, Krewski D. The role of particulate size and chemistry in the association between summertime ambient air pollution and hospitalization for cardiorespiratory diseases. Environ Health Perspect 1997;105(6):614-20.

\section{Authors' response}

We would like to thank the Journal for giving us the opportunity to further clarify our work and to respond to the letter to the editor submitted by Granville, Gephart and Keefe.

The authors of the letter suggest that detecting an association between urban air pollution and daily mortality rates in Canadian cities is surprising. We suggest that not detecting such an effect would be more surprising since such effects have been observed in similar epidemiological studies throughout the world ${ }^{1}$ with little evidence to suggest a population threshold. This implies that there exists an association between relatively low concentrations of air pollution and mortality. We had access to large databases and used sensitive methods of analysis to detect effects.

The authors suggest that the relatively low levels of air pollution in Canada would preclude a mortality effect of the size reported in our paper $(8.2 \%$ increase in mortality). However, this percentage was based on the effects of four pollutants in combination, not just a single pollutant ... see Letters, page 240 